\title{
Mechanical Property of Tailor Made Flax/Glass Fiber Reinforced Hybrid Polyester Composite
}

\author{
K. Arun Prasath, V. Arumugaprabu, P. Amuthakkannan, V. Manikandan
}

\begin{abstract}
The knowledge of mechanical properties of reinforced hybrid composites is very abundant, even though this could be one of the critical issues for many practical applications. This paper has the detailed study and a road to know more about the flax/glass fiber composites and its review on the appliance, property oriented with some of the special properties of the fiber. However, the occurrence of flax fiber is in the cooler regions of western country the worth of flax was more in the replacement of synthetic fibers as a replica of its own property in the application purposes Therefore, the current study was conducted to investigate the strength and performance of glass and flax fiber reinforced hybrid composite by a comprehensive set of experiments. The method of preparation to prepare the composite is by compression molding technique. The final result conclude that (48\%flax/32\% glass) has maximum tensile strength with the sample id 5,(50\%flax/50\%glass) has maximum flexural strength for the sample id 6 and the impact strength is for the ample id 7 (24\%flax/56\%glass) fiber composites.
\end{abstract}

Keywords : Flax/Glass fiber, Polyester Matrix, Hybrid composite, Compression Molding, Mechanical properties.

\section{INTRODUCTION}

$\mathrm{F}_{\text {iber is one of the fibrous materials. It is available in plants }}$ and animals, vegetable tissue, mineral substance. Fibers are often used in manufacture of other materials. It contained more strength, some chemical contents are there and it is strongest among the natural cellulosic fibers. It is extracted from the stem of the flax plant for application purposes. The glass fiber is one of the manmade fibers which have more strength for reliable applications. Polyester resins are the most widely used resin capable of being cured from a liquid or solid state when subject to the right thermoset conditions. The study of thermal characteristics and low velocity drop weight impact property of flax fiber has good evaluation up to $300{ }^{\circ} \mathrm{C}$ and $2500 \mathrm{~N}$, the case of fire resistance there is good observation seen for flax fiber [1]. The experimental study on fluid structure interaction to evaluate the dynamic response of the composite [2].The effect of water absorption in the

Revised Manuscript Received on December 29, 2019.

* Correspondence Author

K.Arun Prasath, Department of Mechanical Engineering, Kalasalingam Academy of Research and Education, Krishnankoil, India Email: arunprasath@klu.ca.in

V.Arumugaprabu*, Department of Mechanical Engineering, Kalasalingam Academy of Research and Education, Krishnankoil, India Email:Email: v.arumugaprabu@klu.ac.in

P.Amuthakkannan, Department of Mechanical Engineering, PSR Engineering College, Sivakasi, India Email: amuthakkannanp@gmail.com

V.Manikandan, Department of Mechanical and Automation, PSN College of Engineering and Technology, Tirunelveli, India Email: vaimanikandan@yahoo.com. basalt/flax composite reinforced with vinyl ester matrix depends upon the fiber loading conditions, similarly interlaminar fracture is said to be an important factor [3]. The mechanical properties of bio-composites are an objective to study about the surface modification on both reinforcement and matrix [4]. The mechanical property of flax fiber bundle/PP composites to compare the performance of glass fiber/PP composite there is improved in surface conditions were identified [5]. While seeing the loss factor and damping factor carbon fiber has better property than the flax fibers [6] Addition of 5\% low melts polyester fiber extra to improve the strength of the composites for coconut sheath fiber as a binding agent [7]. In construction industry, to improve the shear strength steel plate is replaced with carbon fibers for common practices [8]. To evaluate the fracture energy initiation and propagation as well as the crack length under dry and wet conditions using CCM and SBT methods for better results [9]. The multi-layer short natural fiber has better properties and also it is used for various engineering applications [10-11]. In the mechanical and rheological properties of thermoset composites reinforced with lingo cellulosic fibers has better properties and it is used for manufacturing processes and characterizing tests for these composites [12].Unsaturated polyester composites shows good results in the immersion of water at room temperature and with the boiling temperature of composites, noticed the enhanced mechanical properties for non-woven hemp fiber [13],it was found using of carbon fibre as top and bottom end layers for composites, less damages are seen in the structural design, also with good flexural strength [14-15]. The sisal/GFRP, jute/GFRP, sisal/jute/GFRP composite samples are fabricated in that hybrids composite are subjected to mechanical testing such as tensile, flexural and impact test. The presence of natural fiber improves the eco-friendly behavior, and same can effectively utilized for various applications [16-17].The Bio composites filled with natural fibers were commonly seen. In order to extend their application in fire behavior needs to be studied. However, the contact time is a was independent factor of impact energy and presented with a constant value for each lay-up technique of manufacturing are investigated [18-20].The detailed review of the literature shows that, variety of reinforced composites were involved and how they are fabricated and what are the matrix materials used. It gives various opinions on the how composites have used in the materials field of manufacturing. Fibers are extensively used in various fields and have variety of properties that makes it way for various applications, hybrid composites are better property holders for mechanical related applications. 


\section{EXPERIMENTAL DETAILS, FIBER PREPARATION AND MANUFACTURING}

Flax and glass fibers are mixed based on the relative weight percentage values for testing the mechanical properties of various proportions of composite laminates. The fibers are taken according to the relative weight percent of the other fiber used. The different proportions of the hybrid composite laminates gives the opportunity to test and provide a concrete result on the better and suitable proportion yielding required strength and properties. Instead of preheating, the thoroughly mixed fibers are pre-compressed for a certain amount of time to make the fibers active for resin interaction. Pre-compression is applied for only proportions having more flax fiber content compared to glass fiber, as the flax fiber have a small amount of cushion or flocculent nature.

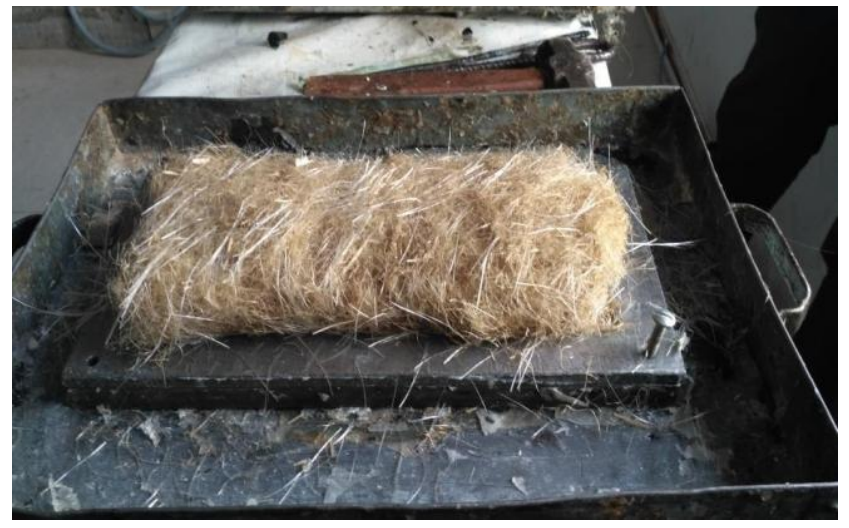

Fig. 1 Flax and glass fibers after thorough mixing

Compression molding is used to fabricate the flax/glass composites with the pressure of $126 \mathrm{kgf} / \mathrm{cm} 2$. The flax fiber is purchased from Varghese fibers Kerala, glass fiber and GP polyester resin from vasvibala resins and fibers Chennai. The various mixtures of flax/glass were undergone for composite preparation with different fiber composition with the curing time of 3hours at room temperature. Then the composite plate was cut accordingly with the given standards to evaluate the mechanical properties of glass/flax composites.

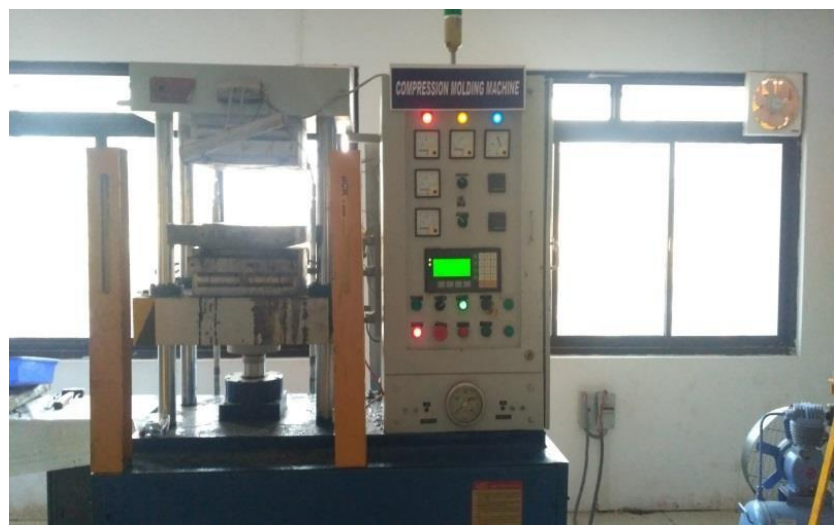

Fig .2 Compression Molding machine used to fabricate composite laminates

\section{RESULT AND DISCUSSION}

In this experimental analysis ten sample of various relative percentages of fibers are used to create composite laminates and three specimens for each testing and nine specimens from each laminate is taken to carry out the testing procedure. The following table 1 and figure 3 gives the detailed view on the fiber content of each sample and the relative weight percentages are also mentioned.

Table-1:Sample Relative Weight Percentage

\begin{tabular}{|c|c|c|c|c|}
\hline Sample & $\begin{array}{l}\text { Fl } \\
\text { ax } \\
\text { (g } \\
\text { m) }\end{array}$ & $\begin{array}{c}\text { Gla } \\
\text { ss } \\
\text { (gm } \\
\text { ) }\end{array}$ & $\begin{array}{c}\text { Wt. } \\
\% \\
\text { of } \\
\text { Flax }\end{array}$ & $\begin{array}{c}\text { Wt.\% } \\
\text { of Glass }\end{array}$ \\
\hline 1 & 80 & 0 & 100 & 0 \\
\hline 2 & 72 & 8 & 90 & 10 \\
\hline 3 & 64 & 16 & 80 & 20 \\
\hline 4 & 56 & 24 & 70 & 30 \\
\hline 5 & 48 & 32 & 60 & 40 \\
\hline 6 & 40 & 40 & 50 & 50 \\
\hline 7 & 24 & 56 & 30 & 70 \\
\hline 8 & 16 & 64 & 40 & 80 \\
\hline 9 & 8 & 72 & 10 & 90 \\
\hline $\begin{array}{l}1 \\
0\end{array}$ & 0 & 80 & 0 & 100 \\
\hline
\end{tabular}

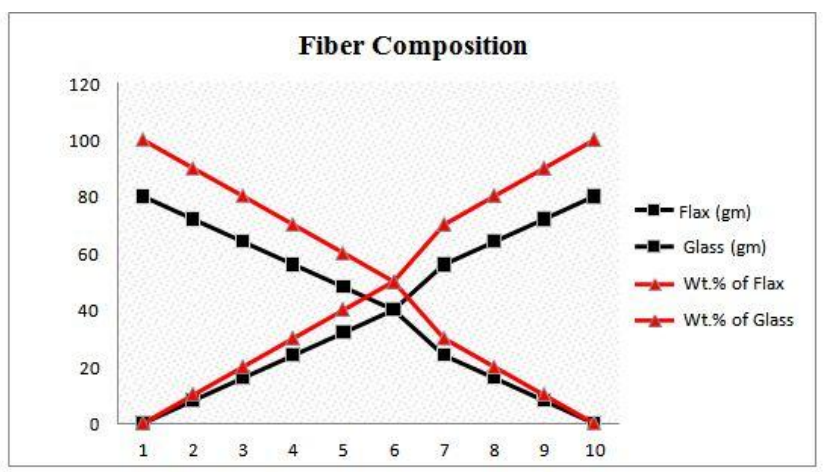

Fig.3 Flax and Glass Content in sample

Each specimen yielding results from tensile, flexural and impact testing will take into consideration and the final plotting is dining with the help of average values of the test results. The following table. 2 shows the test results obtained from each test in $\mathrm{N} / \mathrm{mm}^{2}$, from the results; it is convenient to derive our final conclusion on which sample has highest strength based on average value. The tensile, flexural and impact testing are carried out under ASTM standards ASTM D 638, ASTM D 790 and ASTM D 256 respectively. The test results are plotted on graph having $\mathrm{x}$-axis as sample number and the $y$-axis parameter is taken as strength obtained in each result in $\mathrm{N} / \mathrm{mm}^{2}$. Three specimens for each testing gives nine results for each sample. The average of the three results is calculated and is considered for the discussion into final conclusion. 
Table-II: Test Results (Tensile, Flexural and Impact Test)

\begin{tabular}{|c|c|c|c|c|c|c|c|c|c|}
\hline \multirow{2}{*}{$\begin{array}{c}\text { Sample } \\
\text { ID }\end{array}$} & \multicolumn{3}{|c|}{$\begin{array}{c}\text { Tensile Strength, N/mm } \\
\text { ASTM D } 638\end{array}$} & \multicolumn{3}{c|}{$\begin{array}{c}\text { Flexural Strength, N/mm } \\
\text { ASTM D 790 }\end{array}$} & \multicolumn{3}{c|}{ Impact Strength, N/mm ${ }^{2}$} \\
\cline { 2 - 10 } & 1 & 2 & 3 & 1 & 2 & 3 & 1 & 2 & 3 \\
\hline 1 & 47 & 44 & 41 & 157 & 182 & 164 & 18 & 17 & 19 \\
\hline 2 & 68 & 62 & 34 & 224 & 224 & 217 & 16 & 18 & 17 \\
\hline 3 & 39 & 31 & 25 & 194 & 194 & 256 & 18 & 19 & 18 \\
\hline 4 & 54 & 61 & 50 & 223 & 223 & 268 & 20 & 21 & 18 \\
\hline 5 & 77 & 61 & 54 & 286 & 286 & 285 & 18 & 22 & 19 \\
\hline 6 & 60 & 55 & 75 & 269 & 269 & 299 & 17 & 16 & 18 \\
\hline 7 & 54 & 54 & 76 & 189 & 189 & 243 & 17 & 18 & 20 \\
\hline 8 & 51 & 54 & 94 & 196 & 191 & 194 & 19 & 18 & 19 \\
\hline 9 & 94 & 48 & 51 & 321 & 287 & 293 & 22 & 21 & 19 \\
\hline 10 & 115 & 180 & 68 & 386 & 312 & 402 & 23 & 21 & 23 \\
\hline
\end{tabular}

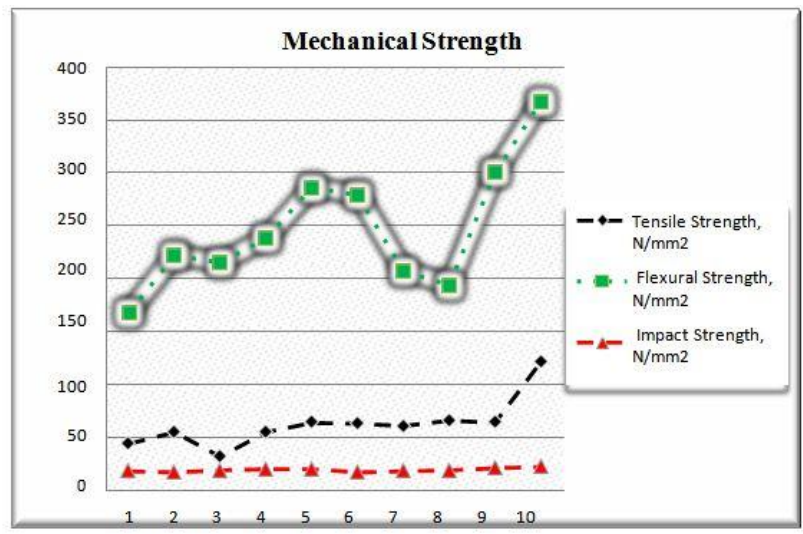

Fig .4 Mechanical Strength

\section{CONCLUSION}

This study focuses on utilizing inexpensive flax and glass fibers as reinforcement towards producing polyester flax/glass composites, thus bringing economic value to flax fibers. The results show us that the pure glass fiber laminate shows maximum strength on all tensile, flexural and impact parameter. From the following graph, we can assume that the samples 5,6,9 and 10 show maximum strength from which, we can conclude that the samples having relatively equal proportions of flax and glass fibers and having high glass content exhibit high tensile, flexural and impact properties.

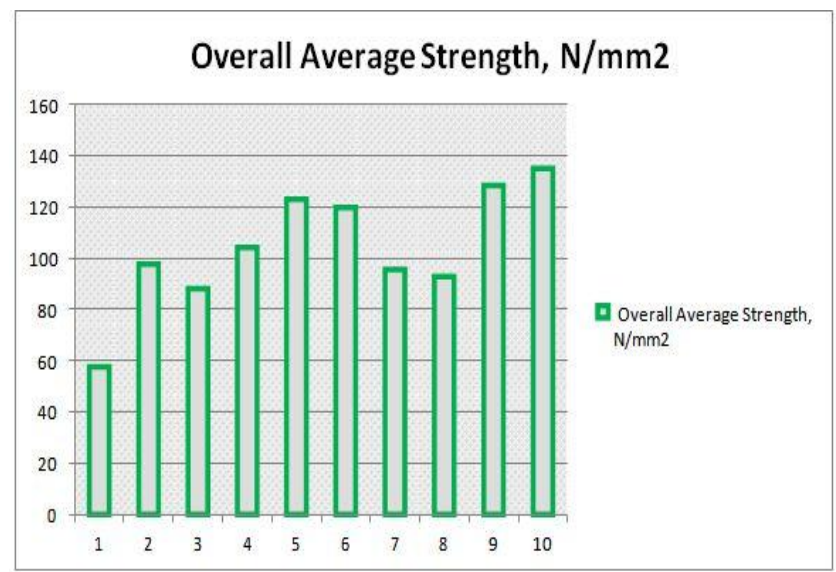

Fig .5 Overall strength values

\section{REFERENCES}

1. Krzysztof Majersk, Barbara Surowska, Jaroslaw Bienias. Comparison of effects of hydrothermal conditioning on mechanical properties of fiber metal laminates. Fiber. Polym. 4 (2018) p.p.7-19.

2. Kenneth S. Vecchio, Fengchun Jiang, Fracture toughness of ceramic-fiber- reinforced metallic-intermetallic-laminate (CFR-MIL) Compos. Struct. 8 (2015) 1- 11

3. Ortiz de Mendibil, L. Aretxabaleta. Impact behaviour of glass fiber-reinforced epoxy/aluminium fiber metal laminate manufactured by Vacuum Assisted Resin Transfer Moulding Compos. Struct. 140 (2016) p.p.118-124.

4. M.Vasumathi and Vela Murali. Effect of alternate metals for use in natural fiber reinforced fiber metal laminates under bending, impact and axial loadings Procedia. Engineer. 64(2013) p.p.562-570.

5. Changsoon Janga, Luca Quagliatob, Mohanraj Murugesana, Dongwook Kima, Cheolsoo Leea, Naksoo. Material property of metal skin sheet moulding compound laminate structures for the production of lightweight vehicles body frame Procedia. Engineer. 207(2017) p.p.878-883.

6. Vahid Daghigh, S.M.R. Khalili, Reza Eslami Farsani. Creep Behavior of Basalt Fiber-Metal Laminate Composites Compos. Part B-Eng. 17(2016) p.p.620-631.

7. Wang X, Song L, Pornwannchai W, Hu Y, Kandola B. The effect of graphene presence in flame retarded epoxy resin matrix on the mechanical and flammability properties of glass fiber-reinforced composites. Compos. A .Appl .Sci .Manuf. 53 (2013) 88-96.

8. Kandare E, Chukwunonso AK, Kandola BK. The effect of fire-retardant additives and a surface insulative fabric on fire performance and mechanical property retention of polyester composites. Fire.Mater. 3 (2011) p.p.143-55

9. Hao Y, Liu F, Shi H, Han E, Wang Z. The influence of ultra-fine glass fibers on the mechanical and anticorrosion properties of epoxy coatings. Prog .Org .Coat. 71 (2011) p.p.188-97.

10. Faruk O, Bledzki AK, Fink H-P, Sain M. Biocomposites reinforced with natural fibers Prog. Polym .Sci. 37 (2012)p.p.1552-96.

11. Kozłowski R, Władyka-Przybylak M. Flammability and fire resistance of composites reinforced by natural fibers. Polym. Adv .Technol. 19(2008) p.p.446-53.

12. Kandola BK. Flame retardant characteristics of natural fibre composites Nat. Polym.1( 2012) p.p.86-117.

13. Manfredi LB, Rodríguez ES, Wladyka-Przybylak M, Vázquez A. Thermal degradation and fire resistance of unsaturated polyester, modified acrylic resins and their composites with natural fibres. Polym. Degrad. Stab. 91(2006) p.p. 255-61.

14. Toldy A, Anna P, Csontos I, Szabó A, Marosi G. Intrinsically flame retardant epoxy resin - fire performance and background - part I. Polym. Degrad .Stab. 92(2007) p.p.2223-30

15. Lim WP, Mariatti M, Chow W, Mar K. Effect of intumescent ammonium polyphosphate (APP) and melamine cyanurate (MC) on the properties of epoxy/glass fiber composites. Compos. B.Eng. 42 (2012) p.p.124-8.

16. Toldy A, Szolnoki B, Marosi G. Flame retardancy of fibre-reinforced epoxy resin composites for aerospace applications. Polym.Degrad.Stab 96 (2011) ,p.p.371-6.

17. Sponton M, Mercado L, Ronda J, Galia M, Cadiz V. Preparation, thermal properties and flame retardancy of phosphorus-and silicon-containing epoxy resins. Polym.Degrad.Stab. 93(2008) p.p.2025-31.

18. Wang X, Hu Y, Song L, Xing W, Lu H, Lv P. Flame retardancy and thermal degradation mechanism of epoxy resin composites based on a DOPO substituted organophosphorus oligomer. Plast. Polym. 51(2010) p.p.2435-45.

19. $\mathrm{Qu} \mathrm{H}, \mathrm{Wu} \mathrm{W}, \mathrm{Hao} \mathrm{J}$, Wang $\mathrm{C}, \mathrm{Xu}$ J. Inorganic-organic hybrid coating-encapsulated ammonium polyphosphate and its flame retardancy and water resistance in epoxy resin. Fire. Mater. 38 (2014),p.p. 312-22.

20. Kim NK, Lin R, Bhattacharyya D. Flammability and mechanica behaviour of polypropylene composites filled with cellulose and protein based fibres: comparative study. Compos. A. Appl. Sci. Manuf. 100 (2017) p.p.215-26.

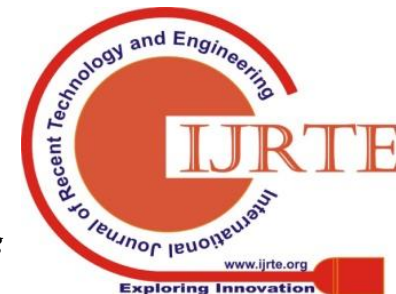




\section{AUTHORS PROFILE}

K. ArunPrasath, working as an Assistant Professor in the Department of Mechanical Engineering ,Kalasalingam Academy of Research and Education, Krishnankoil. He has research experience in the field of cellular manufacturing and published some good works in reputed journals. And also his research extend to composite materials for low velocity applications

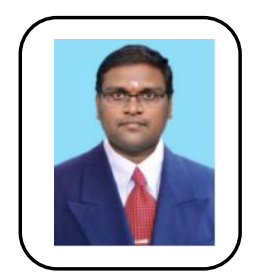

Dr.V.Arumugaprabu, working as an Associate Professor in the Department of Mechanical Engineering ,Kalasalingam Academy of Research and Education, Krishnankoil. He has expertise in the area of red mud filled composite materials and industrial safety. And also he published so many papers in reputed journals.

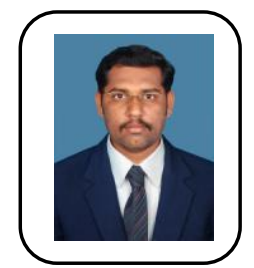

Dr.P.Amuthakkannan, working as an Department of Mechanical Engineering, PSR Engineering College, Sivakasi. His area of interest in basalt fiber polyester composites and mathematical modeling .He published so many papers and reviewer for reputed journals.

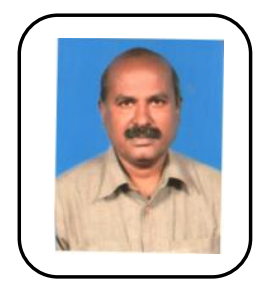

Dr.V.Manikandan, working as Principal, PSN College of Engineering and Technology, Tirunelveli. His area was industrial waste recycling of composite materials and natural fiber composites. And also he published so many papers in reputed journals. 